\title{
Transatlantic editorial: Institutional investigations of ethically flawed reports in cardiothoracic surgery journals
}

\author{
Robert M. Sade, MD, ${ }^{\mathrm{a}}$ Bartosz Rylski, MD, ${ }^{\mathrm{b}}$ Julie A. Swain, MD, ${ }^{\mathrm{c}}$ John W. C. Entwistle III, MD, PhD, ${ }^{\mathrm{d}}$ and \\ DuyKhanh P. Ceppa, MD, ${ }^{\mathrm{e}}$ for the Cardiothoracic Ethics Forum
}

A growing body of evidence suggests that research misconduct has been rising steadily over the past few decades. The mass media have sensationalized high-profile cases of scientific fraud. Several surveys have attempted to define the incidence of scientific misconduct, but the available evidence is unreliable owing mostly to underreporting of misconduct. ${ }^{1}$ An indirect indication of the extent of research misconduct is the incidence of article retractions from the scientific literature, which is tracked by the Retraction Watch database. Among science journals, the number of retractions rose from 114 in the 5-year period 19901994 to 10,738 in the corresponding period 2010-2014, a 94-fold increase. ${ }^{2}$ A well-known survey of early- and mid-career scientists found that $33 \%$ said they had engaged in serious misconduct in the previous 3 years. ${ }^{3}$ The apparent growth in misconduct may be merely an artifact of increased focus on the issue or it may be real, but the question of a recent surge is not as important as the fact that misconduct is widespread and undermines the foundation of science, which is built on honest and transparent investigation.

The federal definition of research misconduct includes 3 topics: fabrication of data, falsification of data, and plagiarism. The integrity of science is endangered by many other major and minor adverse practices, however, such as ignoring important aspects of human-subject requirements; failing to present data that contradict one's own previous research; changing the design, methodology, or results of

\footnotetext{
From the ${ }^{\mathrm{a}}$ Division of Cardiothoracic Surgery, Department of Surgery, and Institute of Human Values in Health Care, Medical University of South Carolina, Charleston, SC; ${ }^{b}$ Department of Cardiovascular Surgery, University Heart Center Freiburg, Freiburg, Germany; ' Department of Cardiovascular Surgery, Icahn School of Medicine at Mount Sinai, New York, NY; ${ }^{\mathrm{d}}$ Division of Cardiothoracic Surgery, Thomas Jefferson University, Philadelphia, Pa; and ${ }^{\mathrm{e} D i v i s i o n}$ of Cardiothoracic Surgery, Department of Surgery, Indiana University School of Medicine, Indianapolis, Ind. Dr Sade's role in this publication was supported by the South Carolina Clinical \& Translational Research Institute, Medical University of South Carolina's Clinical and Translational Science Award Number UL1TR001450. The contents are solely the responsibility of the authors and do not necessarily represent the official views of the National Center for Advancing Translational Science of the National Institutes of Health.

Disclosures: Authors have nothing to disclose with regard to commercial support.

Members of the Cardiothoracic Ethics Forum who contributed to this work: David Blitzer, MD, Andrea J. Carpenter, MD, PhD, DuyKhanh P. Ceppa, MD, Edward P. Chen, MD, Robbin G. Cohen, MD, MMM, Thomas A. D'Amico, MD, Daniel H. Drake, MD, John W.C. Entwistle III, MD, PhD, Paul W.M. Fedak, MD, PhD, Kathleen N. Fenton, MD, Matthias Loebe, MD, PhD, John E. Mayer, MD, Martin F. McKneally, MD, PhD, Walter H. Merrill, MD, Scott J. Millikan, MD, Susan D. Moffatt-Bruce, MD, PhD, Sudish C. Murthy, MD, PhD, Keith S. Naunheim, MD,
}

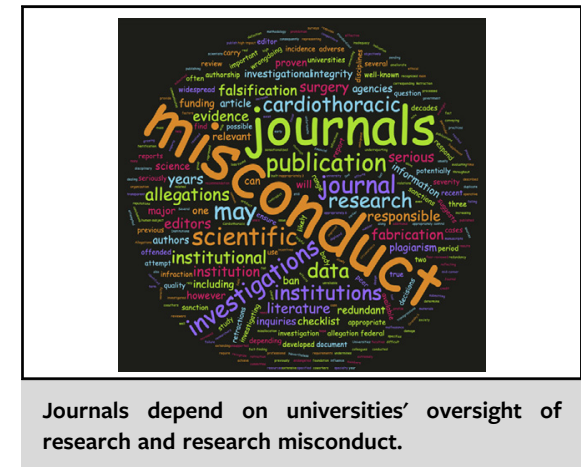

\begin{abstract}
CENTRAL MESSAGE
Institutions are responsible for investigating allegations of research misconduct but lack guidance and consistency, which are needed.
\end{abstract}

a study in response to pressure from a funding source; submitting the same information to more than one publication; and giving authorship credit inappropriately.

Peer-reviewed professional journals are one of the main channels for conveying scientific information, and they

Mark B. Orringer, MD, Shuddhadeb Ray, MD, MPHS, Jennifer C. Romano, MD, Robert M. Sade, MD, Sandra L. Starnes, MD, Julie A. Swain, MD, James S. Tweddell, MD, Richard I. Whyte, MD, and Joseph B. Zwischenberger, MD.

This article has been copublished in The Journal of Thoracic and Cardiovascular Surgery, The Annals of Thoracic Surgery, and the European Journal of CardioThoracic Surgery.

The American Association for Thoracic Surgery requests that this article be cited as: Sade RM, Rylski B, Swain JA, Entwistle JWC, Ceppa DP, for the Cardiothoracic Ethics Forum. Transatlantic editorial: institutional investigations of ethically flawed reports in cardiothoracic surgery journals. J Thorac Cardiovasc Surg. 2020;159:1903-5

Address for reprints: Robert M. Sade, MD, Medical University of South Carolina, 30 Courtenay Dr, Suite 277, MSC 295, Charleston, SC 29425-2270 (E-mail: sader@ musc.edu).

J Thorac Cardiovasc Surg 2020;159:1903-5

0022-5223/\$36.00

Copyright $@ 2020$ Jointly between The American Association for Thoracic Surgery, The Society of Thoracic Surgeons, and the European Association for Cardio-Thoracic Surgery. Published by Elsevier Inc.

https://doi.org/10.1016/j.jtcvs.2019.11.011 
are responsible for ensuring the quality and integrity of the information they publish. The major journals in the field of cardiothoracic surgery have identified more publication misconduct in recent years than they had earlier, reflecting the evidence that suggests increasing misconduct throughout scientific disciplines. Allegations of misconduct come from several sources, including, for example, peer reviewers who find evidence of possible wrongdoing, authors who allege wrongdoing by coauthors, and colleagues who charge misconduct by coworkers or competitors. The most common ethical violations in cardiothoracic journals have been redundant publication, but have also included plagiarism, misallocation of authorship, and the most serious infractions: fabrication or falsification of data.

We have previously described how cardiothoracic journals respond to proven misconduct. ${ }^{4,5}$ When the infraction is redundant (duplicate) publication, sanctions range from a letter of reprimand to a 1- or 2-year ban on publication in the journal, depending on the severity of redundancy. The editor may notify the authors' home institutions and the editors of other relevant journals. For more serious offenses that undermine the veracity of the literature, such as falsification or fabrication of data, the article will be retracted, and the editor may ban publication for 2 or more years, up to a permanent ban, again depending on the severity of the infraction. Notification of the sanction may be sent to the authors' specialty society organization for further disciplinary action.

The editorial staffs of scientific journals take allegations of misconduct seriously and respond with appropriate sanctions if they are proven true, up to and including prohibition from publishing for a specified time in the offended journal (and sister journals when they are notified), as well as the most serious sanction, retraction of the article from the scientific literature. The operative term here is "proven true," which is more difficult to achieve than it might seem. Some allegations can be investigated and resolved by journal editors, such as redundant publication, failure to obtain required institutional review committee approval, and plagiarism. Others, such as fabrication and falsification of data, however, require extensive inquiries that demand fact-finding resources beyond those available to journals. In such cases the journals must rely on the responsible institutions, usually universities, to carry out in-depth investigations to determine the facts of each case and report their findings to relevant entities, such as funding institutions, including federal agencies, and offended journals.

Institutions often fail to carry out adequate investigations and reach objectively sound conclusions, even when these are mandated by government agencies that have funded the study in question. ${ }^{6}$ The need for a national body to oversee misconduct investigations has been recognized for decades, yet still does not exist. ${ }^{7}$ Universities in particular may have incentives to downplay transgressions by members of their faculties, such as potentially adverse financial effects of research funding losses, damage to the reputations of well-known researchers and consequently of the university itself, and loss of publications in high-impact journals. ${ }^{8}$ Most likely, however, the reported widespread inadequacy of institutional investigations is related to factors such as the absence of any standardized format, peer review of inquiries, and quality control or oversight for investigations.

In an attempt to ameliorate this unfortunate circumstance, a group of experts in research misconduct representing a wide range of disciplines and agencies met recently and developed a checklist for evaluating institutional investigations in the hope that investigating institutions would use the document to ensure that their inquiries were thorough and executed appropriately. ${ }^{6}$

Cardiothoracic journals have been hampered in dealing appropriately with some allegations of misconduct when institutional investigations have been poorly managed, have reached ambiguous or unsupported decisions, or have conducted their investigation extremely slowly, often extending over several years. Journal editors recognize that when acting alone they are likely to have little influence on correcting institutional malfeasance in investigating allegation of misconduct. Nevertheless, journals can attempt to help institutions provide reports that editors find helpful in making appropriate decisions about submitted or published manuscripts that may be seriously flawed.

To that end, the major cardiothoracic surgery journals have developed a checklist against which universities and other institutions can measure their own investigational processes before or after sending their investigational reports to an affected journal (Appendix 1). This document is modified from the Supplement to Gunsalus, Marcus, and Oransky. ${ }^{6}$ When a cardiothoracic surgery journal receives an allegation of misconduct and communicates that allegation to the responsible institution, it will include a note that specifies the allegation, along with relevant additional materials, and a recommendation that the institution uses the checklist to ensure that their report is as useful as possible to the journal.

Whether the responsible institution changes or improves its investigational process is up to the institution, of course, but at a minimum the journal will have deployed a potentially effective tool in its efforts to protect the integrity of the cardiothoracic surgery literature.

We are grateful to Paul Kurlansky, MD, for bringing the issue of inadequate university investigations to our attention.

\section{References}

1. National Academies of Sciences, Engineering, and Medicine. Addressing research misconduct and detrimental research practices: current knowledge and issues, 
Fostering Integrity of Research. Washington, DC: National Academies Press; 2017.

2. The Retraction Watch Database. Version 1.0.5.5. Available at: http:// retractiondatabase.org/RetractionSearch.aspx. Accessed August 12, 2019.

3. Martinson BC, Anderson MS, de Vries R. Scientists behaving badly. Nature. 2005; 435:737-8.

4. Sade RM, for the Cardiothoracic Ethics Forum. Sanctions for research misconduct in cardiothoracic surgery journals. Ann Thorac Surg. 2016;102:685-7.

5. Sade RM, for the Cardiothoracic Ethics Forum. Sanctions for research misconduct in cardiothoracic surgery journals. J Thorac Cardiovasc Surg. 2016;152:661-3.

6. Gunsalus CK, Marcus AR, Oransky I. Institutional research misconduct reports need more credibility. JAMA. 2018;319:1315-6.

7. Gunsalus CK, McNutt MK, Martinson BC, Faulkner LR, Nerem RM. Overdue: a US advisory board for research integrity. Nature. 2019;566:173-5.

8. Institute of Medicine. Evolution of Translational Omics: Lessons Learned and the Path Forward. Washington, DC: National Academies Press; 2012: 122.

Key Words: ethics, health policy, professional affairs

\section{APPENDIX 1. A NOTE TO THE RESPONSIBLE INSTITUTION}

Cardiothoracic surgery journals have the responsibility to ensure the integrity of the scientific information they publish. Recent decades have seen a substantial increase in the number of allegations of scientific misconduct throughout science, and surgery journals are no exception. Lacking the required resources, we must rely on the institutions in which such research has taken place to investigate the allegations and determine the facts of the case. Investigations of misconduct allegations often suffer from lack of clear guidance for their conduct, so we have taken the liberty of constructing a checklist designed to aid the evaluation and reporting of your investigation. We hope you find this checklist helpful, as it will help the journal to better assess the nature of the investigation and the conclusions.

A checklist for planning or reviewing research integrity investigations

\begin{tabular}{|c|c|c|c|}
\hline & Yes & No & In part \\
\hline \multicolumn{4}{|l|}{ In general, a research integrity investigation should } \\
\hline Interview the appropriate individuals & $\square$ & $\square$ & $\square$ \\
\hline Secure the relevant factual data that are reviewed by appropriate experts & $\square$ & $\square$ & $\square$ \\
\hline Identify appropriate questions to pursue and use a meaningful approach to securing the answers & $\square$ & $\square$ & $\square$ \\
\hline Have sufficient scope to address the scientific integrity issues & $\square$ & $\square$ & $\square$ \\
\hline \multicolumn{4}{|l|}{ Investigative Committee } \\
\hline The Investigative Committee (the Committee) should have membership appropriate to the task & $\square$ & $\square$ & $\square$ \\
\hline $\begin{array}{l}\text { The Committee should include at least } 1 \text { cardiothoracic surgeon or other cardiothoracic investigator, conversant with the } \\
\text { research area }\end{array}$ & $\square$ & $\square$ & $\square$ \\
\hline The Committee should include at least one member with expertise in the area who is external to the responsible institution. & $\square$ & $\square$ & $\square$ \\
\hline The charge to the committee should be clear & $\square$ & $\square$ & $\square$ \\
\hline Conflicts of interest of Committee members should be solicited and reported & $\square$ & $\square$ & $\square$ \\
\hline Standards of due process and confidentiality should be followed & $\square$ & $\square$ & $\square$ \\
\hline The respondent should have an opportunity to identify conflicts among Committee members & $\square$ & $\square$ & $\square$ \\
\hline The investigative committee should have access to all necessary expertise or resources for a thorough investigation & $\square$ & $\square$ & $\square$ \\
\hline \multicolumn{4}{|l|}{ Evidence of misconduct } \\
\hline Evidence relevant to the allegation should be properly sequestered and protected from tampering & $\square$ & $\square$ & $\square$ \\
\hline The evidence considered in the investigation should be clearly described & $\square$ & $\square$ & $\square$ \\
\hline The respondent should be offered an opportunity to reply to the allegations and the report & $\square$ & $\square$ & $\square$ \\
\hline The Committee should consider and address whether important evidence was unavailable to them & $\square$ & $\square$ & $\square$ \\
\hline If seemingly pertinent evidence was not reviewed, an explanation should be provided & $\square$ & $\square$ & $\square$ \\
\hline A need for further evidence or additional analysis should be determined & $\square$ & $\square$ & $\square$ \\
\hline A list of individuals who were interviewed should be provided & $\square$ & $\square$ & $\square$ \\
\hline $\begin{array}{l}\text { A list of others who should have been but were not interviewed should be provided, along with the reasons for not } \\
\text { interviewing. }\end{array}$ & $\square$ & $\square$ & $\square$ \\
\hline $\begin{array}{l}\text { Additional questions that should have been asked or evidence examined to reach a supportable conclusion should be } \\
\text { considered }\end{array}$ & $\square$ & $\square$ & $\square$ \\
\hline \multicolumn{4}{|l|}{ The Report } \\
\hline An executive summary should be included & $\square$ & $\square$ & $\square$ \\
\hline Relevant institutional policies should be articulated and applied to the allegations & $\square$ & $\square$ & $\square$ \\
\hline The report should be written in clear and understandable language & $\square$ & $\square$ & $\square$ \\
\hline The allegations should be clearly presented & $\square$ & $\square$ & $\square$ \\
\hline The scope of the investigation should be sufficient to address the scientific integrity issues & $\square$ & $\square$ & $\square$ \\
\hline The report should clearly state its findings and its conclusions & $\square$ & $\square$ & $\square$ \\
\hline The report's findings should support its conclusions & $\square$ & $\square$ & $\square$ \\
\hline The report and its findings should be made available to all relevant parties & $\square$ & $\square$ & $\square$ \\
\hline
\end{tabular}

Adapted from Gunsalus et al. 